http://jmscr.igmpublication.org/home/ ISSN (e)-2347-176x ISSN (p) 2455-0450

crossref DOI: https://dx.doi.org/10.18535/jmscr/v8i3.47

Journal Of Medical Science And Clinical Research

\title{
Correlative Study of Thyroid Dysfunction with Blood Sugar Levels and Serum Lipid Levels in Post Menopausal Women
}

\author{
Authors \\ Dr Mohammad Zahid Labrez ${ }^{1}$, Dr Ashok Kumar ${ }^{2 *}$ \\ ${ }^{1}$ Junior Resident, Department of Medicine, Patna Medical College \& Hospital, Patna \\ ${ }^{2}$ Associate Professor, Department of Medicine, Patna Medical College \& Hospital, Patna \\ *Corresponding Author \\ Dr Ashok Kumar
}

\begin{abstract}
Background: Thyroid disorder is common in the general population and the extensiveness increase with age. Diabetic patients have a higher extensiveness of thyroid disorders compared with the normal population. Because patients with one organ autoimmune disease are at risk of developing other autoimmune disorders, and thyroid disorders are more common in females tan male. So we want to find out any correlation between thyroid dysfunction with blood sugar levels and serum lipid levels in post menopausal women.

Methods: It was a cross sectional study. One hundred post menopausal women were randomly included in study over a period of one and half year between June 2018 to November 2019 after matched with inclusion and exclusion criteria and followed up in the Medicine OPD, of Patna Medical College \&Hospital, Patna.

Results: 100 postmenopausal women were screened for thyroid dysfunction in this cross sectional study. Prevalence of hypothyroidism was found to be $22 \%$ and of subclinical was $8 \%$ and of thyrotoxicosis was $2 \%$. It is seen that thyroid dysfunction has a correlation with duration of menopause with maximum patients having more than 10 years of menopause.

Conclusion: Thyroid dysfunction is seen in a significant percentage of postmenopausal women. The predominant dysfunction seen is overt hypothyroidism, followed by subclinical hypothyroidism. The incidence of thyrotoxicosis was very less in these women. Hypothyroidism was seen more in women with increasing age and increasing duration of menopause and was associated with an increased BMI.

Keywords: overt hypothyroidism, Subclinical hypothyroidism, Postmenopausal women, Dyslipidemia, Diabetes mellitus, HDL, LDL, TG, TC.
\end{abstract}

\section{Introduction}

The American Association of Clinical Endocrinologists (AACE) stated that, millions of women with unresolved menopausal-like symptoms, even those taking estrogen, may be suffering from undiagnosed thyroid disease. Symptoms like fatigue depression, mood swings and sleep disturbances are usually associated with menopause but they could also be the signs of hypothyroidism. Most of the women nowadays spend one third to one half of their lives postmenopausal. The prevalence of overt hypothyroidism usually increases with leading age. 
$6-8 \%$ of women (10\% over the age of 60$)$ and $3 \%$ men are likely to have subclinical hypohyroidism. The annual risk of developing clinical hypothyroidism is about $4 \%$ when subclinical hypothyroidism is related with positive thyroid peroxidase antibodies (TPO) ${ }^{1}$. Screening has been recommended which can effectively diagnose the existence of subclinical thyroid dysfunction in postmenopausal women.

In the general population thyroid dysfunction is becoming very common and the prevalence usually increases with age ${ }^{1}$. The screening of thyroid function by modern assays is both decsive and not costing a great deal. Screening for thyroid dysfunction is indicated in certain high risk groups such as neonates and the elderly.

So far hypothyroidism is found to be the most common thyroid disorder in the adult population and its prevalence is more common in older women, usually it is autoimmune in origin and presenting as either primary atrophic hypothyroidism or Hashimoto's thyroiditis. Pituitary or hypothalamic disorders can result in secondary hypothyroidism very rarely. About 4 million people in the United States are going through thyroxine replacement therapy who are suffering from hypothyroidismy ${ }^{2}$.

Hyperthyroidism is much less common compared to hypothyroidism and women are more likely to have hyperthyroidism with a female to male ratio of 9:1. The most common etiology is Grave's disease and involves primarily young adults. The older age groups are more likely to affect by the toxic multinodular goiters.

Prevalence of thyroid dysfunction is more common in diabetic patients compared with the non-diabetic population. The reason behind this fact is: patients with one organ specific autoimmune disease are at risk of developing other autoimmune disorders, and thyroid disorders are more common in females, and with no surprise it was observed that upto $30 \%$ of female type 1 diabetic patients have thyroid disease ${ }^{2}$.

The prevalence of postpartum thyroiditis in diabetic patients is three times compared to normal women. A number of studies have also reported a higher than normal prevalence of thyroid disorders in type 2 diabetic patients with hypothyroidism being the most common disorder ${ }^{2}$.

Diabetes control is affected by the presence of thyroid dysfunction. Hyperthyroidism is frequently associated with poor glycemic control and elevated insulin requirements. There is underlying increased hepatic gluconeogenesis, rapid gastrointestinal glucose absorption, and probably increased insulin resistance. Indeed thyrotoxicosis can lead to latent diabetes.

In practice there are several implications for patients with both diabetes and hyperthyroidism. Firstly, the hyperglycemia may improve with treatment of thyrotoxicosis so the screening of glucose intolerance needs to be considered cautiously in hyperthyroid patients.

Secondly, unexplained poor hyperglycemia should be considered for underlying hyperthyroidism in diabetic patients.

Lastly, physicians need to emphasize on possible deterioration in poor glycemic control and maintain treatment accordingly in diabetic patients with hyperthyroidism. Restoration of euthyroidism will lower blood glucose level.

In hypothyroidism wide ranging changes in carbohydrate metabolism are observed, clinical manifestation of these abnormalities is rarely conspicuous. However, the reduced rate of insulin degradation may decrease the exogenous insulin requirement. The presence of hypoglycaemia is uncommon in isolated thyroid hormone deficiency and should raise the possibility of hypopituitarism in a hypothyroid patient.

More importantly, hypothyroidism is associated with several abnormalities in plasma lipid metabolism, including elevated level of triglyceride and low density lipoprotein (LDL) cholesterol concentrations. Subclinical hypothyroidism aggravates the coexisting dyslipidemia which is very common in type 2 diabetes and furthet increases the risk of cardiovascular diseases. Appropriate thyroxine 
replacement will prevent the lipid abnormalities. The prevalence of autoimmune thyroid disorders is more likely to be found in young women with type 1 diabetes. The incidence of transient thyroid dysfunction is common in the postpartum period and warrants routine screening with serum thyroid stimulating hormone (TSH) 6-8 weeks after delivery.

Fluctuation in glucose control during the transient hyperthyroidism followed by hypothyroidism is typical of the postpartum thyroiditis. Screening of thyroid function tests in these women is very important since approximately 30\% will not recover from the hypothyroid phase and will require thyroxine replacement. Recurrent thyroidditis with subsequent pregnancies is common.

Hypothyroidism can also lead to secondary dyslipidemia. Strong correlation of hypothyroidism and atherosclerosis, as well as its clinical manifestations, is wellknown ${ }^{3}$. Thyroid disorders including overt as well as subclinical hypothyroidism considerably alter lipid profile and promote cardiovascular disease ${ }^{4}$. Studies consistently demonstrate elevated levels of serum total cholesterol, low density lipoprotein cholesterol (LDL-C), apolipoprotein B, lipoprotein (a) and possibly triglycerides in individuals with overt hypoyhyroidism ${ }^{5}$.

Increased diastolic blood pressure (as a result of increased systemic vascular resistance) and altered lipid profile (elevated levels of total cholesterol, LDL- cholesterol and apolipoprotein B) is usually seen in hypothyroid patients ${ }^{6}$.

\section{Methods}

This was a cross sectional study. One hundred post menopausal women were randomly included in study over a period of one and half year between June 2018 to November 2019 after application of inclusion and exclusion criteria and followed up in the Medicine OPD, of Patna Medical College \& Hospital, Patna.

\section{Inclusion Criteria}

1) Postmenopausal women (with more than 2 years of amenorrhea)
2) Patients will be taken from OPD and IPD, Department of Medicine, $\mathrm{PMCH}$

\section{Exclusion Criteria}

- Patients on hormone replacement therapy

- Ovarian and uterine malignancy

- Drugs- Propranolol, iopanoic acid, iodide, amiodarone, salicylates, phenytoin, glucocorticoids, lithium, amphetamine. Sertraline, aminogluthetimide, interleukin, dopamine, somatostatin, octreotide, heroin use.

- Known case of cirrhosis of liver.

- Known case of nephrotic syndrome

- Reno vascular hypertension.

\section{Statistical Methods}

Descriptive statistical analysis has been carried out in the present study. Results on continuous measurements are presented on Mean \pm SD (MinMax) and results on categorical measurements are presented in Number (\%). Significance is assessed at $5 \%$ level of significance. $2 \times 4,3 \times 4$ Fisher Exact test has been used to find the significance of study parameters on categorical scale between two or more groups. 95\% Confidence Interval has been computed to find the significant features. Confidence Interval with lower limit more than $50 \%$ is associated with statistical significance.

\section{Statistical Software}

The Statistical software named SPSS 17.0, Stata 8.0, MedCalc 9.0.1 and Systat 11.0 were used for the data analysis and Microsoft word and Excel have been used to generate graphs, tables etc.

\section{Results}

100 postmenopausal women were screened for thyroid dysfunction in this cross sectional study. Prevalence of hypothyroidism was found to be $22 \%$ and of subclinical was $8 \%$ and of thyrotoxicosis was $2 \%$. It is seen that thyroid dysfunction has a correlation with duration of menopause with maximum patients having more than 10 years of menopause. 
Table: 1. Thyroid status

\begin{tabular}{|l|c|c|c|}
\hline Thyroid status & Number $(\mathrm{n}=100)$ & $\%$ & $95 \% \mathrm{CI}$ \\
\hline Euthyroid & 68 & 68.0 & $58.34-78.33$ \\
\hline Hypothyroid & 22 & 22.0 & $15.00-31.07$ \\
\hline Known case of hypothyroidism & 6 & 6.0 & $3.34-9.45$ \\
\hline Subclinical hypothyroid & 8 & 8.0 & $4.11-15.00$ \\
\hline Thyrotoxicosis & 2 & 2.0 & $0.5-7.80$ \\
\hline
\end{tabular}

Table: 2. Correlation of Thyroid dysfunction of patients and age in years

\begin{tabular}{|l|c|c|c|c|c|}
\hline \multirow{2}{*}{ Age in years } & Total no. of & \multicolumn{4}{|c|}{ Thyroid dysfunction } \\
\cline { 3 - 6 } & patients & Normal & Hypo & Sub clinical & Thyrotoxicosis \\
\hline $45-49$ & 7 & $7(100 \%)$ & $0(0 \%)$ & $0(0 \%)$ & $0(0 \%)$ \\
\hline $50-54$ & 31 & $27(87.1 \%)$ & $3(9.7 \%)$ & $1(3.2 \%)$ & $0(0 \%)$ \\
\hline $55-59$ & 33 & $20(60.6 \%)$ & $9(27.3 \%)$ & $3(9.1 \%)$ & $1(3 \%)$ \\
\hline $60-64$ & 29 & $14(48.3 \%)$ & $10(34.5 \%)$ & $4(13.8 \%)$ & $1(3.4 \%)$ \\
\hline Total & 100 & $68(68 \%)$ & $22(22 \%)$ & $8(8 \%)$ & $2(2 \%)$ \\
\hline Inference & $\begin{array}{l}\text { Age in years is significantly associated with thyroid dysfunction with } \mathrm{P}=0.052+(4 \times 4 \text { Fisher } \\
\text { Exact test) }\end{array}$
\end{tabular}

Table: 3. Correlation of Thyroid dysfunction of patients and Duration of menopause

\begin{tabular}{|c|c|c|c|c|c|}
\hline \multirow{2}{*}{$\begin{array}{l}\text { Duration } \\
\text { menopause }\end{array}$} & \multirow{2}{*}{$\begin{array}{l}\text { Total no. of } \\
\text { patients }\end{array}$} & \multicolumn{4}{|c|}{ Thyroid dysfunction } \\
\hline & & Normal & Hypo & Sub clinical & Thyrotoxicosis \\
\hline $0-4$ years & 23 & $18(78.3 \%)$ & $4(17.4 \%)$ & $1(4.3 \%)$ & $0(0 \%)$ \\
\hline 5-9 years & 40 & $31(77.5 \%)$ & $6(15.0 \%)$ & $2(5 \%)$ & $1(2.5 \%)$ \\
\hline $10-14$ years & 34 & $19(55.9 \%)$ & $10(29.4 \%)$ & $4(11.8 \%)$ & $1(2.9 \%)$ \\
\hline $15-19$ years & 3 & $0(0 \%)$ & $2(66.7 \%)$ & $1(33.3 \%)$ & $0(0 \%)$ \\
\hline Total & 100 & $68(68 \%)$ & $22(22 \%)$ & $8(8 \%)$ & $2(2 \%)$ \\
\hline Inference & \multicolumn{5}{|c|}{$\begin{array}{l}\text { Duration of menopause is statistically associated with thyroid dysfunction with } \mathrm{P}=0.079 \text { ( } 4 \text { x } 4 \\
\text { Fisher Exact test) }\end{array}$} \\
\hline
\end{tabular}

There was a significant correlation between thyroid dysfunction and BMI. Maximum patients with thyroid dysfunction were overweight or had grade 1 obesity.

$15.2 \%$ of hypothyroid patients and $6.2 \%$ of subclinical hypothyroid patients were found to have type 2 diabetes mellitus.
Dyslipidemia was found to be statistically associated with thyroid dysfunction with a

$\mathrm{P}$ value of 0.014 . The pattern of dyslipidemia seen was that $36.3 \%$ of hypothyroid Patients had hypercholesterolemia and $27.2 \%$ of patients had a combination of hypercholesterolemia \& hypertriglyceridemia.

Table: 4. Correlation of Thyroid dysfunction of patients and BMI

\begin{tabular}{|c|c|c|c|c|c|}
\hline \multirow[b]{2}{*}{$\operatorname{BMI}\left(\mathrm{kg} / \mathrm{m}^{2}\right)$} & \multirow{2}{*}{$\begin{array}{l}\text { Total no. of } \\
\text { patients }\end{array}$} & \multicolumn{4}{|c|}{ Thyroid dysfunction } \\
\hline & & Normal & Нyро & $\begin{array}{c}\text { Sub } \\
\text { clinical }\end{array}$ & $\begin{array}{l}\text { Thyrotoxicos } \\
\text { is }\end{array}$ \\
\hline Up to 22.9 & 39 & $34(87.8 \%)$ & $2(6.1 \%)$ & $1(2.0 \%)$ & $2(4.1 \%)$ \\
\hline $23-24.9$ & 10 & $9(58.8 \%)$ & $1(4.4 \%)$ & $0(0 \%)$ & $0(0 \%)$ \\
\hline $25.0-29.9$ & 34 & $20(29.4 \%)$ & $10(29.4 \%)$ & $4(11.8 \%)$ & $0(0 \%)$ \\
\hline$>30$ & 17 & $5(14.2 \%)$ & $9(52.9 \%)$ & $3(17.6 \%)$ & $0(0 \%)$ \\
\hline Total & 100 & $68(68.0 \%)$ & $22(22.0 \%)$ & $8(8.0 \%)$ & $2(2.0 \%)$ \\
\hline Inference & \multicolumn{5}{|c|}{$\begin{array}{l}\text { BMI }(\mathrm{kg} / \mathrm{m} 2) \text { is significantly associated with thyroid dysfunction with } \mathrm{P}<0.001 * * \\
(3 \mathrm{x} 4 \text { Fisher Exact test) }\end{array}$} \\
\hline
\end{tabular}


Table: 5. Correlation of Thyroid dysfunction of patients and Diabetics

\begin{tabular}{|c|c|c|c|c|c|}
\hline \multirow[b]{2}{*}{ Diabetics } & \multirow[b]{2}{*}{$\begin{array}{c}\text { Total no. of } \\
\text { patients }\end{array}$} & \multicolumn{4}{|c|}{ Thyroid dysfunction } \\
\hline & & Normal & Нуро & $\begin{array}{l}\text { Sub } \\
\text { clinical }\end{array}$ & Thyrotoxicosis \\
\hline Absent & 67 & $43(64.2 \%)$ & $17(25.4 \%)$ & $6(9 \%)$ & $1(1.5 \%)$ \\
\hline Present & 33 & $25(75.8 \%)$ & $5(15.2 \%)$ & $2(6.1 \%)$ & $1(3 \%)$ \\
\hline Total & 100 & $68(68 \%)$ & $22(22 \%)$ & $8(8 \%)$ & $2(2 \%)$ \\
\hline Inference & \multicolumn{5}{|c|}{$\begin{array}{l}\text { Presence of diabetics is not statistically associated with thyroid dysfunction witl } \\
\mathrm{P}=0.531(2 \times 4 \text { fisher Exact tet })\end{array}$} \\
\hline
\end{tabular}

Table: 6. Correlation of Thyroid dysfunction of patients and Dyslipidemia

\begin{tabular}{|l|c|c|c|c|c|}
\hline \multirow{2}{*}{ Dyslipidemia } & Total no. of & \multicolumn{4}{|c|}{ Thyroid dysfunction } \\
\cline { 3 - 5 } & patients & Normal & Hypo & Subclinical & Thyrotoxicosis \\
\hline Absent & 64 & $49(76.6 \%)$ & $8(12.5 \%)$ & $5(7.8 \%)$ & $2(3.1 \%)$ \\
\hline Present & 36 & $19(52.8 \%)$ & $14(38.9 \%)$ & $3(8.3 \%)$ & $0(0 \%)$ \\
\hline Total & 100 & $68(68 \%)$ & $22(22 \%)$ & $8(8 \%)$ & $2(2 \%)$ \\
\hline Inference & $\begin{array}{l}\text { Dyslipidemia is significantly associated with thyroid dysfunction with } \mathrm{P}=0.014 *(2 \times 4 \\
\text { fisher Exact test) }\end{array}$ \\
\hline
\end{tabular}

\section{Discussion}

100 postmenopausal women attending the OPD and IPD were included in the study and screened for thyroid dysfunction.

Out of these 100 patients $22 \%$ patients were found to have hypothyroidism, $8 \%$ had subclinical hypothyroidism, $2 \%$ patients were found to have thyrotoxicosis. Remaining 68 patients were euthyroid. A population-based survey reported by Tunbridge et al conducted 30 years ago revealed a prevalence in the general population in the UK of around $2.7 \%$ in females (10-fold less in males) and of undiagnosed disease in around $0.5 \%$ of women. There are few data on prevalence specifically in elderly populations. In one UK community survey by Parle et al of 1210 subjects aged over 60 years only one person was found to have undiagnosed overt hyperthyroidism. Another larger and more recent prevalence study from the same group in the UK has indicated a prevalence of undiagnosed hyperthyroidism of $0.3 \%$ in a large group aged over 65 years with an additional prevalence of previously diagnosed overt hyperthyroidism of $0.3 \%$. Another survey of 1442 subjects in Sweden indicated that $2 \%$ of over 60's had thyrotoxicosis on screening.

The prevalence of subclinical hypothyroidism in the US population is about $4 \%$ to $8.5 \%$ in those without known thyroid disease. ${ }^{[7]}$. The prevalence increases with age and in women older than 60 years of age subclinical hypothyroidism is present in upto $20 \%$ There is a correlation seen between increasing age of the patients and incidence of hypothyroidism, this is consistent with the fact that incidence of hypothyroidism increases with increasing age and is probably related to aging of the thyroid gland and atrophic thyroiditis ${ }^{[8]}$.

There is also a correlation seen between duration of menopause and thyroid dysfunction with maximum hypothyroid patients having more than 10 years of menopause. ${ }^{[9,10]}$ The thyroid menopause connection is complex. It actually stems from close interactions between hormones the thyroid produces and the reproductive organs. Because hormones produced by the thyroid regulate metabolism, they directly influence the activity of reproductive glands. In addition, estrogen and progesterone directly affect thyroid uptake receptor sites by blocking or allowing them to function. A association is seen with the thyroid dysfunction and BMI but weight gain is known to be an effect of hypothyroidism. ${ }^{[11,12]}$

$15.2 \%$ of hypothyroid patients and $6.2 \%$ of subclinical hypothyroid patients were found to have type 2 diabetes mellitus. In one study the overall prevalence of thyroid disease was found to be $13.4 \%$ in diabetic patients and was highest in Type 1 diabetic females (31.4\%) and lowest in Type 2 diabetic males. 
Significant association is observed between thyroid dysfunction and dyslipidemia. It is known that hypothyroidism is one of the most common etiologies of secondary dyslipidemia. The pattern of dyslipidemia seen in this study is that $34 \%$ of patients had hypercholesterolemia and $27.2 \%$ had a combination of hypercholesterolemia \& hypertriglyceridemia. This is in accordance with the pattern seen in other studies.

\section{Conclusion}

Thyroid dysfunction is seen in a significant percentage of postmenopausal women. The predominant dysfunction seen is overt hypothyroidism, followed by subclinical hypothyroidism. The incidence of thyrotoxicosis was very less in these women. Hypothyroidism was seen more in women with increasing age and increasing duration of menopause and was associated with an increased BMI.

Postmenopausal women are at an increased risk for artherosclerosis and heart disease and the added presence of secondary dyslipidemia due to hypothyroidism in these women will add to the risk of atherosclerosis and its vascular complications. The presence of increased BMI as a consequence of undiagnosed hypothyroidism will further add to the risk factors for vascular complications.

Even subclinical hypothyroidism was associated with dyslipidemia and increased BMI.Hence screening can be recommended for hypothyroidism in postmenopausal women especially in those with increasing age, duration of menopause and overweight women to evaluate and correct dyslipidemia so as to prevent adverse artherosclerotic cardiovascular complications and to prevent morbidity and mortality.

A larger study is required to be conducted in postmenopausal women to evaluate these factors.

\section{References}

1. Harrison's Principles of Internal Medicine; $20^{\text {th }}$ edition; Vol 2: 2698-2707

2. Barnett D.M., Krall L.P. History of Diabetes In; Editors Kahn CR, Weir GC, King GL, Jacobson AM, Moses AC, Smith RJ, Joslin's Diabetes Mellitus, $15^{\text {th }}$ edition. Boston, BI Publications Private Ltd. 2005; $1-80$.

3. Duntas LH, 2002 Thyroid disease and lipids. Thyroid 12: 287-293.

4. Duntas LH, Brenta G, Med Clin North Am. 2012 Mar;96(2):269-81

5. Pearce EN.J Clin Endocrinol Metab. 2012 Feb;97(2):326-33.

6. Endo Krynol Pol, Mar-Apr 2005; 56(2): 194-202.

7. Santoro N, Randolph JF Jr, Reproductive hormones and the menopause transition. Obstet Gynecol Clin North Am. 2011 Sep;38(3):455-66.

8. Smith KE, Judd HL. Menopause and postmenopause. In: DeCherney H,Pernoll ML, eds. Current Obstetric and Gynecologic Diagnosis and Treatment. $8^{\text {th }}$ ed. Appleton \& Lange 1994; 1030-1050.

9. Butler L, Santoro N. The reproductive endocrinology of the menopausal transition. steroids. 2011 jun.76(7):627-35.

10. Kannel WB, Hjortland MC, McNamara PM, et al. Menopause and cardiovascular disease: the Framingham study. Ann Intern Med. Oct 1976; 85(4): 447-52.

11. Assmann G, Cullen P, Schulte H. The Munster Heart Study (PROCAM). Results of follow-up at 8 years. Eur Heart J. Feb 1998; 19 Suppl A: A2-11.

12. Ladenson PW, Singer PA, Ain KB, Bagachi N, Bigas ST, Levy EG,et al. American Thyroid Association guidelines for detection of thyroid dysfunction. Archives of Internal Medicine. 2000; 160: 1573-5. 